\title{
Consumo cultural e midiático dos jovens face às mídias
}

\section{sociais:}

\author{
Uma experiência no nordeste brasileiro
}

\section{Youth Media and Cultural Consumption in Social Media:}

\section{An Experience in Northeastern Brazil}

Vitor Braga

Jornalista e doutor em Comunicação. Professor da UFS. Membro do Grupo de Pesquisa em Marketing e do Grupo de Pesquisa em Interações, Tecnologias digitais e Sociedade (GITS). Universidade Federal do Sergipe, Programa de Pós-graduação em Comunicação, São Cristóvão(SE), Brasil.

Matheus P.M. Felizola

Publicitário e Administrador de Empresas. Doutor em Ciências Sociais e Professor do PPGCOM/PPGCI da Universidade Federal de Sergipe. Universidade Federal do Sergipe, Programa de Pós-graduação em Comunicação, São Cristóvão (SE), Brasil.

Jane A. Marques Mestra e Doutora em Ciência da Comunicação. Professora da Universidade de São Paulo - USP. Universidade de São Paulo, Escola de Artes, Ciências e Humanidades, São Paulo (SP), Brasil. 


\section{Introdução}

Este artigo é resultado de uma pesquisa que vem sendo realizada no interior de Sergipe, como parte do projeto de pesquisa "Jovem e consumo midiático em tempos de convergência: Brasil profundo", fruto de uma cooperação nacional entre instituições de ensino superior em três regiões do Brasil - Sul, Norte e Nordeste ${ }^{1}$. A pesquisa teve por objetivo investigar as práticas de consumo midiático e o uso das plataformas digitais de jovens entre 18 e 24 anos que fossem moradores das zonas urbana, rural, quilombola e ribeirinha.

Em Sergipe, foi realizada pelo Grupo de Pesquisa em Marketing (UFS) ${ }^{2}$ em 10 municípios que compõem a Microrregião de Propriá: Amparo de São Francisco, Brejo Grande, Canhoba, Cedro de São João, Ilha das Flores, Neópolis, Nossa Senhora de Lourdes, Propriá, Santana do São Francisco e Telha. Neste artigo, trazemos o resultado de uma análise de conteúdo (BARDIN, 2016) de 100 entrevistas semiestruturadas com os jovens desses municípios.

O levantamento dos dados foi realizado entre os anos de 2016 e 2018, e as reflexões surgiram a partir do cenário de convergência midiática já bastante difundido por autores nacionais e internacionais, mas com poucas pesquisas relacionadas aos habitantes do interior (que denominamos de "Brasil Profundo"), rico cenário de diversidade regional, social, econômica e cultural representado pelas pequenas cidades brasileiras.

É importante ressaltar que a terminologia "Brasil Profundo" foi uma escolha da pesquisadora brasileira Nilda Jacks (UFGRS), inspirada pelo livro México Profundo. Una civilización negada de Batalla (1990). Na obra, o autor aborda a civilização formada por toda a diversidade cultural construída a partir da evolução histórica do México. No nosso caso, estamos tratando de duas civilizações diferentes; o termo "Brasil Profundo" se aplica por buscarmos jovens de comunidades distantes dos grandes centros e provenientes de origens quilombolas, rurais, e economicamente associados a grupos marginalizados.

\footnotetext{
${ }^{1} \mathrm{O}$ projeto é uma promoção da Universidade Federal do Rio Grande do Sul (UFRGS), da Universidade Federal do Pará (UFPA) e da Universidade Federal de Sergipe (UFS), contando ainda com o apoio de instituições de ensino superior das regiões onde as três promotoras se localizam.

${ }^{2}$ Composto por professores do Departamento de Comunicação Social, estudantes dos cursos de graduação em Publicidade e Propaganda, Jornalismo e Audiovisual, bem como aqueles do Programa de Pós-Graduação em Comunicação.
} 
A escolha da área geográfica de abrangência desse estudo esteve voltada para a necessidade de conhecer a dinâmica do chamado interior sergipano. Sendo assim, ao assumir a decisão de investigar a Microrregião de Propriá, optamos por investigar uma área compreendida como distante da zona de influência da região metropolitana de Aracaju - no intuito de compreender o consumo cultural e midiático dos jovens considerando o contexto contemporâneo, caracterizado pela convergência dos meios, e em condições de acesso às redes e às Tecnologias de Informação e Comunicação (TICS) com particularidades, se comparada a sua realidade com a dos jovens de contextos urbanos nas capitais. Haveria, neste caso, uma distância geográfica e também social na Microrregião de Propriá - composta, por sua vez, por pequenas cidades cuja maior tem apenas 28451 habitantes, conforme o IBGE Cidades (2010).

\section{A comunicação no "Brasil profundo": entre as mídias de massa e as mídias sociais}

Nosso trabalho parte de uma base conceitual composta por três eixos: o consumo e o que se entende por cultura do consumo (CANCLINI, 2010; SLATER, 2002); a relação com os dispositivos comunicacionais móveis conforme a perspectiva da convergência midiática (JENKINS, 2009; THOMPSON, 2014); e como essas regiões do interior do Brasil, especialmente no Nordeste do país, promovem um fenômeno interpretado como "rurbanidade” (CIMADEVILLA, 2008; WEISHEIMER, 2005).

O consumo midiático, primeiro eixo de nosso estudo, se refere às práticas das pessoas em torno do que a mídia oferece: os meios - televisão, rádio, jornal, internet, sites, mídias sociais, dispositivos etc. - e os conteúdos oferecidos por esses meios - informações, publicidade, entretenimentos, conexões, conversações, relacionamentos, etc. Além disso, analisa-se o contexto de envolvimento com os produtos midiáticos como parte do consumo cultural, baseados em Toaldo e Jacks (2017).

Canclini (2001) já havia alertado que o consumo estaria cada vez mais inteligível na sociedade em que o sólido se evapora. O consumo, em nosso trabalho, é assim entendido como um componente importante para a compreensão dos jovens na sociedade contemporânea, pois estaríamos presenciando a solidificação de uma cultura de consumo (CANCLINI, 2010) que interfere na forma como as pessoas se apropriam dos dispositivos de comunicação. Tais apropriações estariam em curso em busca de um estilo de vida em que os indivíduos buscariam construir, sustentar e negociar suas subjetividades, gerenciando estrategicamente uma variedade de recursos materiais e simbólicos (SLATER, 2002). Temos assim um 


\section{ALCEU}

ISSN: $2175-7402$

consumo que perpassa os meios de comunicação de massa, mas também os próprios indivíduos operando como consumidores de conteúdo de suas redes nas mídias sociais.

No que tange à questão da convergência midiática, não a entendemos em nosso trabalho como um processo que abrange mudanças profundas nas relações comerciais e interpessoais. Conforme Aquino (2017), isso envolve uma complexa reengenharia de produção e um realinhamento dos esforços de marketing, auxiliando na criação de uma nova arquitetura comercial e de uma nova distribuição de serviços de informação e comunicação. Tal convergência é observada tanto no tocante às mudanças culturais na produção de conteúdo quanto nos novos papéis de receptores ou usuários de mídias. Analisamos o consumo midiático a partir de um modo contemporâneo de colaboração, caracterizado como difuso e lúdico, ao mesmo tempo que leva à distração dos consumidores devido à amplitude e à diversidade de conteúdo circulado nos meios digitais (JENKINS, 2009).

Assim como Jenkins (2009), a nossa interpretação do fenômeno da convergência avança para uma transformação da cultura e inteligência de consumo, com novas trilhas de comunicação, novos formatos de conexões e mídias cada vez mais difusas e dispersas. Thompson (2014) já observava uma centralidade da mídia nas relações sociais contemporâneas, percebendo o desenvolvimento dos meios de comunicação como (re)orientadores da interação social. Conforme o referido autor: "Com o desenvolvimento dos meios de comunicação, a interação se dissocia do ambiente físico, de tal maneira que os indivíduos, podem interagir uns com os outros ainda que não partilhem do mesmo ambiente espaço temporal” (p. 119).

A respeito da questão da "rurbanidade", de acordo com Weisheimer (2005, p. 7), quando os pesquisadores brasileiros voltam o seu olhar para a especificidade dos jovens do chamado "interior" do país, dois aspectos chamam a atenção: "sua participação nas dinâmicas migratórias e a persistência da invisibilidade social dessa juventude". É nesse contexto que nosso corpus empírico se encontra inserido e conectado com suas redes - seja nas relações em copresença, seja nas mídias sociais.

No primeiro aspecto, apontamos que os processos migratórios respondem pelo esvaziamento e pela masculinização especialmente dos jovens residentes no meio rural. Os indicadores do IBGE (2013) demonstram que em 1950 a população não residente nas capitais correspondia a 63\% da população total brasileira; já no ano de 2000 essa proporção havia reduzido para 18,8\%. Outro fator importante a comentar é que a partir da década de 1990 ocorreu uma migração de jovens, principalmente na faixa 


\section{ALCEU}

ISSN: $2175-7402$

etária de 20 a 24 anos (CAMARANO \& ABRAMOVAY, 1999), sendo que as mulheres representavam 52\% desse total. Já no segundo aspecto - acerca da "invisibilidade" -, Weisheimer (2005) entende tratar-se de uma situação que reflete a exclusão social ocorrida no país, impedindo esses jovens de se tornarem sujeitos de direitos sociais e alvos de políticas públicas, inviabilizando o rompimento da própria condição de exclusão. Além dessa condição difícil, essa juventude convive com situações de não reconhecimento, preconceito e marginalidade (WEISHEIMER, 2005).

Tal "situação de invisibilidade" permanece também na produção acadêmica no país a respeito desse público, pois temos um pequeno número de publicações sobre o tema. Em um levantamento de todas as áreas realizado por Weisheimer (2005), durante 15 anos, foram registrados apenas 50 trabalhos no total. Em um ambiente disperso, marcado pelas tecnologias digitais, temos os dispositivos móveis como importantes mediadores da comunicação do jovem com a sua rede social, quer sejam nas ambiências digitais de sites e aplicativos, quer sejam na produção de conteúdo hipermídia - imagético, textual, sonoro e audiovisual - por meio das potencialidades oferecidas por esses aparelhos conectados em redes sem fio. Munidos desses aparelhos nesse contexto "rurbano" (CIMADEVILLA, 2008), temos também uma descentralização na produção de conteúdo, que tradicionalmente esteve a cargo de empresas de comunicação.

\section{Metodologia}

Para o levantamento dos dados, utilizamos da técnica de entrevistas orientadas para a resposta, distinta das que são orientadas para a informação. Segundo Lessard-Hébert et al (1990, p. 162), a entrevista orientada para a resposta “(...) caracteriza-se pelo fato de o entrevistador manter o controle no decurso de todo o processo. Ela é, na maioria das vezes, estruturada ou, pelo menos, semiestruturada e é referenciada a um quadro preestabelecido".

A amostra obtida foi de 100 (cem) entrevistas realizadas com jovens, de ambos os sexos, entre 18 e 24 anos, residentes na Microrregião de Propriá. Por se tratar de uma pesquisa envolvendo seres humanos, esclarecemos que o projeto nacional teve sua aprovação no comitê de ética da Universidade Federal do Rio Grande do Sul (UFRGS) - instituição coordenadora do projeto -, assim como foi aprovado pela CAPES.

As cidades que a compõem estão localizadas no leste sergipano, algumas fazendo divisa com Alagoas. Segundo dados estimados do IBGE (2017), a Microrregião possui uma área de 1014,9 km² e uma 
população de 94220 mil habitantes; as mulheres representam $51,5 \%$ da população residente, e os homens, $48,5 \%$.

Tendo o Rio São Francisco passando por várias cidades, temos aqui muitas comunidades ribeirinhas e a prática da pesca e da agricultura como importantes atividades econômicas (IBGE, 2013). Segundo dados da PNAD Contínua (IBGE, 2017), a partir de critérios envolvendo jovens na faixa etária (de 15 a 19 anos e dos 20 a 24 anos), havia mais de 20 milhões de habitantes nessa localidade pesquisada.

Nas entrevistas, a abordagem foi semiaberta a partir de um roteiro que permita aprofundamento de questões mais pertinentes, sem aumentar a amplitude das perguntas e prejudicar a comparação da análise de conteúdo, realizada com o auxílio do software NVivo (versão 12). A análise de conteúdo foi baseada em três fases, conforme orienta Bardin (2016): pré-análise, exploração do material e tratamento, e interpretação dos dados obtidos. Para sistematizar a análise de conteúdo realizada, aplicamos a esses nós - e seus respectivos subnós - cinco categorias, conforme o Quadro 1.

Quadro 1: Categorias criadas, com seus respectivos nós.

\begin{tabular}{|l|l|}
\hline Categorias & Nós \\
\hline \multirow{2}{*}{$\begin{array}{l}\text { 1. Acesso a aparelhos de comunicação de } \\
\text { massa }\end{array}$} & - Meios analógicos \\
& - Plataformas de consumo audiovisual \\
& - Frequência de uso dos aparelhos \\
\hline \multirow{2}{*}{ 2. Consumo na comunicação de massa } & - Abrangência da programação da mídia \\
& - Consumo audiovisual \\
\hline 3. Posse e uso dos dispositivos móveis & - Emissoras de rádio \\
& - Emissoras de TV \\
\hline 4. Interações com grupos sociais & - Condição de acesso à internet \\
& - Usos dos dispositivos móveis \\
\hline & - Formas de contato com a família \\
\hline
\end{tabular}




\begin{tabular}{|l|l|}
\hline & - Formas de contato com os amigos \\
& - Grupos com que se relaciona \\
\hline \multirow{3}{*}{ 5. Usos da internet e das mídias sociais } & - Navegação na internet \\
& - Mídias sociais utilizadas \\
& - Usos de grupos nas mídias sociais \\
& - Usos das mídias sociais \\
\hline
\end{tabular}

Fonte: pesquisa de campo.

\section{Análise dos dados}

Em nossa amostra, boa parte dos respondentes $(43,1 \%)$ tinha 18 anos e morava na zona urbana (63\%), embora 31,3\% tenham afirmado morar na zona rural; 3,4\%, em colônia de pescadores; e 2,3\%, em comunidades quilombolas. É importante observar que, como as cidades da amostra são pequenas, os limites entre as zonas urbanas e rurais são muito pequenos, de modo que as características do rural estão muito próximas ao urbano - assim como o contrário também acontece.

Em relação à escolaridade dos entrevistados, 63\% tinham até nível médio incompleto; 28,8\%, nível médio completo; 7,5\%, nível superior incompleto; e apenas 0,7\%, nível superior completo. Esses dados eram esperados, pois nos municípios investigados somente um (Propriá) possuía uma instituição de ensino superior. Embora todas as cidades possuam ao menos uma escola estadual, muitos optam por estudar no ensino médio em Propriá, por oferecer um ensino de melhor qualidade. O percentual de jovens entrevistados sem emprego foi de $85,4 \%$; dentre os $14,6 \%$ que declararam possuir empregos formais, o maior percentual $(87,8 \%)$ era trabalhador do comércio. No tocante à renda, a maioria dos entrevistados (56,6\%) possuía renda média de até $\mathrm{R} \$ 1$ mil reais, e 22,8\% afirmaram não possuir renda própria.

Nos próximos tópicos, apresentamos o aporte teórico e os resultados obtidos com a análise de conteúdo das entrevistas. Por questões éticas, visando preservar a identidade dos participantes, citamos apenas o nome fictício e a cidade onde a pessoa reside. As menções dos entrevistados preservam também as características da fala oral; portanto estão mantidas mesmo com falhas ortográficas e/ou gramaticais. 


\subsection{Acesso aos meios de comunicação de massa}

Notamos o distanciamento dos entrevistados no que diz respeito aos meios impressos, tendo em vista a pequena quantidade dos que declaram ter o hábito de ler revistas, jornais ou livros. Destes, apenas um consome revistas em quadrinhos, e ninguém declara ler livros com frequência. Ficam mais restritos à leitura de obras paradidáticas obrigatórias para a conclusão do curso (ensino médio ou superior). Parte desse distanciamento deve-se a uma baixa oferta desses meios na Microrregião, visto que apenas uma das dez cidades (Propriá) possuía banca de revistas.

Sobre as plataformas de consumo audiovisual, o YouTube ${ }^{3}$ é um importante canal digital, haja vista ser citado por vários entrevistados. Inferimos que essa capilaridade se explica por essa mídia oferecer uma programação de nicho, muitas vezes difícil de ser atendida por outros meios: por exemplo, vídeos de tutoriais e "blogueiras". Como atesta uma entrevistada:

Ah...eu uso muito o YouTube, assisto muito vídeo, tutorial de tudo. Eu assisto clipes...deixa eu ver, viu? Blogs das blogueiras, tutoriais, tudo... (Entrevistada mulher 1, Canhoba)

A questão da convergência de aparelhos como smartphones é um ponto favorável ao YouTube, que consegue oferecer serviços para diversas plataformas. Em menor escala, tivemos a menção de serviços como streaming de vídeos, em especial a $\mathrm{Netflix}^{4}$, para o consumo de séries e filmes, às vezes com mais frequência do que os canais de televisão.

Em relação à posse de aparelhos, todos os jovens entrevistados possuem smartphones de uso pessoal. Outros dispositivos comunicacionais são de uso compartilhado: computadores, tablets e notebooks. Algo já esperado, visto que a maioria dos jovens da Microrregião está em situação de baixa renda (IBGE, 2013). Observarmos, ainda, que determinados aparelhos compõem um hábito familiar compartilhado, absorvido pelos jovens para acompanhar a programação, independentemente do interesse efetivo que possuam.

E a rádio, é... eu uso só em casa, porque minha avó coloca e aí acabo escutando, né, não é uma coisa que eu gosto, mas acabo escutando porque também é importante. (Entrevistada mulher 2, Cedro de São João)

\footnotetext{
${ }^{3}$ www.youtube.com

${ }^{4}$ www.netflix.com
} 
No que tange à frequência de uso, destacamos especialmente os dispositivos comunicacionais móveis, sendo os smartphones os de maior frequência. Em alguns casos, chegam a atrapalhar a rotina do sono, o que pode ser reflexo da constância no uso:

O que mais se usa é celular né, smartphone o dia inteiro [risos]. Até dormindo às vezes cê acorda pra... pra usar. (Entrevistada mulher 3, Telha)

O rádio e a televisão são normalmente mais acessados em turnos específicos, devido à sua disponibilidade ou à programação de interesse. Computador ou notebook são utilizados apenas para trabalho ou estudo. Muitos deles inclusive fazem uso destes em locais como bibliotecas ou laboratórios de informática das escolas estaduais ou das Universidades em Propriá e Neópolis 5 .

Os jornais, as revistas e os telefones residenciais (ou fixos) nunca são usados pelos entrevistados. Os dois primeiros podem ser justificados pelo fato de não ter revistas ou jornais locais nas cidades investigadas com circulação permanente. Destacamos, ainda, que não há uma grande oferta de serviços de telefonia na região, impedindo o uso residencial e também dificultando o uso de dados móveis, pois em muitas áreas rurais os jovens relataram dificuldade na conexão.

Notamos que as mídias tradicionais permanecem ativos com suas particularidades, enquanto as novas mídias servem às comunicações mais fluidas, associadas aos conceitos de cultura de convergência (JENKINS, 2009) e de comunicação mediada (THOMPSON, 2014). Os jovens entrevistados demonstram maior aproximação com os meios digitais. O serviço de vídeo on demand, por exemplo, já é realidade e tende a ganhar mais mercado.

\subsection{Consumo na comunicação de massa}

No que se refere à programação dos meios de comunicação de massa, observamos pequena preferência pelos conteúdos nacionais, especialmente quando eles se referem à televisão. Por outro lado, quando citam o rádio, há prioridade pela programação local, em especial pela das emissoras da Microrregião. É interessante notar esse efeito de o conteúdo variar em sua abrangência ao mudar a plataforma de consumo. O mesmo acontece quando os jovens se referem ao consumo pela internet: há uma preferência por sites, blogs e páginas com conteúdo nacional. O consumo dos jovens tem uma inclinação para séries, telejornais, novelas e futebol, com prevalência do conteúdo nacional em relação ao

\footnotetext{
${ }^{5}$ As únicas na Microrregião são a Universidade Tiradentes (UNIT) e a Universidade Federal de Sergipe (UFS).
} 
local. Em parte, essa preferência se justifica pois não existem programas locais produzidos na Microrregião, mas apenas conteúdo transmitido da capital sergipana.

Em relação ao consumo audiovisual, destacam-se os programas de notícias, os filmes, as telenovelas, os desenhos animados, os programas esportivos e as séries, nessa ordem. Existem alguns horários preferidos, dependendo da grade de programação televisiva e das rotinas diárias de cada entrevistado. Outro aspecto interessante de notar é o crescimento no consumo de séries, especialmente as veiculadas em canais digitais de streaming, como a Netflix. O YouTube também teve muita adesão, principalmente vlogs, tutoriais e vídeo-aulas, que os auxiliam na preparação para os estudos.

Sobre o consumo de rádio, as principais programações de interesse desses jovens são as de notícias e as de música. Muitas vezes, os familiares deixam o rádio ligado, e isso é feito, em geral, enquanto se dedicam a outros afazeres. O rádio se apresenta também como um companheiro de atividades cotidianas de parte dos jovens entrevistados, que cita acessá-lo por meio de seus smartphones. Outro destaque é a capacidade de divulgar notícias da região, muitas vezes difícil na televisão ou em outros meios, justamente por estarem sediadas em Aracaju e privilegiarem notícias da capital ou as nacionais.

Rádio eu ouço muito as notícias do nosso dia a dia aqui, tipo FM. saber as notícias do município e da região vizinhas. (Entrevistado homem 1, Amparo do São Francisco)

Não por acaso, as emissoras de rádio mais ouvidas são justamente as que abordam programação local, sendo a rádio Xodó FM, de Nossa Senhora de Lourdes, a mais mencionada. Outras figuram com menor destaque, como a Ilha FM (Neópolis) e a Propriá (FM). Apenas a rádio Jovem Pan foi citada dentre as nacionais, especialmente pelas músicas e notícias.

As emissoras de TV citadas são as afiliadas da Globo, Record e SBT. Todas essas variam a programação local com a nacional, atendendo ao interesse dos jovens; porém há preferência pela Globo em relação às demais. Em algumas localidades, as emissoras só veiculam programação nacional por só captarem sinal de antenas parabólicas.

\subsection{Posse e uso dos dispositivos móveis}

Em relação à condição de acesso à internet, percebemos que a maioria obtém acesso por meio de redes wi-fi, principalmente em suas residências. É interessante como a disponibilidade de serviços de internet sem fio por empresas locais modificou essa condição de acesso, que costumava ser por meio de 
lan houses - que ainda existem, porém em menor número. Angeluci e Galperin (2012) já apontaram a popularidade no acesso a essas TICS no Brasil pelos jovens das classes que corpus empírico também enquadra, especialmente na interlocução com suas redes por meio das mídias sociais. A popularidade do acesso às lan houses caiu a partir de aparelhos e serviços para acesso à internet de casa pelo jovens da Microrregião, embora exista reclamação devido à "lentidão" na velocidade de conexão.

Outra questão frequente está associada a redes wi-fi de vizinhos ou de órgãos públicos que em alguns momentos do dia disponibilizam acesso aberto à população. Isto ocorre por dois fatores: os jovens têm dificuldade de conexão às redes de dados móveis, devido à baixa cobertura na região das operadoras; e por dificuldades financeiras, precisando assim reduzir os custos com telefonia pessoal.

Tinha wi-fi, mas eu cancelei, porque eu não tava usando muito. Aí quando eu quero fazer alguma pesquisa no notebook, alguma coisa, aí eu pego da minha vizinha, o wi-fi, que aí a gente compartilha. (Entrevistada mulher 4, Nossa Senhora de Lourdes)

Notamos também o uso de serviços de dados móveis, optando pela operadora Vivo por garantir a maior cobertura na Microrregião, independentemente do plano; principalmente para aqueles que moram ou se deslocam para zonas rurais ou povoados mais distantes.

Sobre os dispositivos de acesso à internet, os smartphones foram mencionados pela maioria dos jovens como os principais, principalmente pela mobilidade e disponibilidade que tais aparelhos oferecem e por serem capazes de dar conta de praticamente todo o consumo midiático em que eles têm interesse.

Principalmente celular, que é muito mais prático hoje em dia. É um dispositivo que tem todas as ferramentas que eu preciso. (Entrevistado homem 2, Amparo de São Francisco)

Os dispositivos móveis são utilizados na maior parte do tempo, por permitirem acesso e construção de suas subjetividades nas postagens, especialmente para acompanhar atividades dos amigos ou para conversação. Percebemos também que as mídias sociais assumem finalidades diversas, como vendas por meio de aplicativos de mensagens.

Tenho muita venda pelo WhatsApp; tenho um grupo de pessoas. Como a cidade é pequena, eu tenho um grupo de pessoas. como eu estou agora no ramo do Comércio eu fiz um grupo, e qualquer dúvida sobre questão de medicamentos. Entrega, manda no Zap endereço, tudinho, onde é, que eu mando o rapaz entregar já, tudo por ele. (Entrevistado homem 3, Amparo de São Francisco)

No caso do jovem em questão, assim como de outros, a preferência pelo WhatsApp deve-se também em parte ao tipo de aparelho em posse pela população: os smartphones, em vez do telefone 
residencial ou do computador pessoal. Podemos inferir, com base em nossa observação, que o acesso a tais aparelhos garantiu assim uma capacidade comunicativa que, no caso de grande parte dos moradores da Microrregião, sequer existia, considerando o fato de muitos não possuírem linhas telefônicas em suas residências ou sinal de rádio em áreas rurais.

O uso desses dispositivos para o consumo de músicas, sejam estas em aplicativos de streaming de músicas ou por meio de vídeos musicais (no YouTube), também foi mencionado. A mobilidade é mais uma vez reiterada, pois eles realizam outras atividades paralelas. Pudemos assim observar como esses dispositivos conseguem realizar múltiplas funções e dispensam o uso de vários outros.

\subsection{Interações com grupos sociais}

Sobre as formas de contato com a família, apenas a presença física é preferencial. Isso porque os jovens tendem a se relacionar com a família pessoalmente, em casa ou nos encontros nas casas dos familiares, mesmo para os que não moram na mesma cidade.

Família, muitos mora fora, muitos mora em Aracaju. Aqui em Cedro mesmo só mora meu pai, minha mãe e meus avós. Tipo, primo, tudo, o resto, a maioria, né todos não, tão tudo fora, tipo Aracaju, aí a gente mantém contato por telefone mesmo, ou então quando a gente vai lá. Sempre quando a gente vai lá passa muito tempo. (Entrevistado homem 3, Cedro de São João)

Interessante notarmos como as chamadas telefônicas são importantes na interação dos jovens com os familiares, e muitos justificam isso pelo fato de seus parentes, especialmente os mais velhos, não utilizarem canais digitais. Quando mencionam as mídias sociais, o Facebook e o WhatsApp 6 são as que mais atendem a essa finalidade de comunicação. Tanto as conversas privadas quanto os grupos são mencionados; estes últimos auxiliam na manutenção das relações a distância com parentes, bem como na articulação dos eventos familiares.

Quando os jovens são questionados sobre as formas de contato com os colegas de trabalho ou de estudo, existe uma oscilação entre o uso das mídias sociais e o contato presencial, embora usem canais digitais para essa interlocução. Sendo assim, as mídias operam de forma complementar, muitas vezes perdurando o contato feito ao longo do dia na escola, no trabalho ou em outros ambientes.

Tipo, hum..., a escola aqui mesmo da turma, a gente cria um grupo do WhatsApp. Ai quando é trabalho, alguma coisa, a gente sempre, é, divide assim, equipe... Nas turmas a gente divide em equipe, aí para cada

\footnotetext{
${ }^{6}$ https://www.whatsapp.com/
} 
trabalho ou alguma coisa a gente cria um outro grupo pra falar só do trabalho da escola, entendeu? (Entrevistada mulher 5, Neópolis)

Ao questionarmos sobre as formas de contato com os amigos, percebemos uma oscilação entre a presença física e o uso das TICs. No primeiro caso, ter contato pessoal com os amigos é preferível, se compararmos aos colegas de trabalho ou de estudo, pela informalidade e pela intenção afetiva, emocional, que certas relações profissionais ou educacionais não possuem.

Interessante notarmos esse trânsito dos jovens na Microrregião para encontrar os amigos, que muitas vezes se deslocam do centro da cidade para algum povoado. Outro padrão comum é a manutenção das relações de amizade desses jovens com os ex-colegas de estudo, especialmente em grupos de exalunos no WhatsApp. Por sinal, o aplicativo é o principal canal digital para esses jovens. Metade deles mencionou o referido aplicativo, que também ajuda na manutenção de relações com pessoas distantes.

Pela internet, pelo WhatsApp. Nós manda mensagem para eles lá ver, e eles acaba respondendo para eu que tô aqui em Lourdes. (Entrevistada mulher 6, Nossa Senhora de Lourdes)

O Facebook é mais utilizado para interação com as postagens da rede social, com comentários e curtidas. Para as mensagens privadas notamos haver um distanciamento gradativo desse canal, em relação ao WhatsApp e ao Instagram ${ }^{7}$. Percebemos uso convergente dessas mídias sociais (JENKINS, 2009; JENKINS et al, 2014): um diálogo começa com um comentário no Instagram, segue para uma mensagem privada no WhatsApp e gera compartilhamento no Facebook. Temos, assim, o comportamento tratado no estudo de Humphreys (2018), que discorre sobre os rastros deixados pelos usuários nas postagens; por conseguinte, isso leva a ações entre múltiplos canais, sem aberturas e fechamentos muito claros.

No que tange, por fim, aos grupos com os quais se relaciona, pudemos confirmar uma tendência mais frequente com amigos, colegas de estudo e familiares da idade dos jovens. Embora mencionem os pais, os tios e os avós, de fato eles dão a preferência a irmãos e primos, principalmente no contato por meio das TICs.

As alterações que as redes e mídias digitais promovem Thompson (2014, p. 20) trata por interação mediada online, "as novas formas de ação e interação que foram criadas pela comunicação mediada por computador que ocorre em ambientes on-line." O caráter dessa interação mediada favorece o diálogo, mesmo que a interação seja de muitos para muitos; ou seja, pode-se atingir um grande número de pessoas

\footnotetext{
${ }^{7}$ https://www.instagram.com/
} 
e também ser atingido e, ainda assim, estabelecer aproximações com indivíduos e temas de maior interesse.

\subsection{Usos da internet e das mídias sociais}

Ao tratarmos da navegação na internet, são muitas as menções dos respondentes, mostrando a variedade de opções eleitas dependendo da necessidade do momento. Sendo assim, excluindo o uso das mídias sociais, aparecem em destaque o acesso a sites noticiosos e a ferramentas de busca, seja para pesquisas em geral ou as relacionadas a estudo. Os sites noticiosos encabeçam a lista, pois, dentre os fatores apontados, existe uma necessidade de os jovens se manterem informados sobre a Microrregião e o país - valores culturalmente aceitos pela sociedade brasileira.

Dentre as temáticas mencionadas, variam informações de editorias de política, de cidades, de esportes e de celebridades. $O$ interesse em se manter informado também está relacionado à necessidade de estar bem preparado para prestar seleções e concursos.

Eu utilizo também, eu sempre gosto de acessar pra ficar bem informado sobre o que tá acontecendo no mundo. Tudo que abrange de forma geral, até porque eu já to me preparando pro Enem, aí já tenho que ficar atualizado de tudo. (Entrevistado homem 4, Neópolis)

As ferramentas de busca, principalmente o $G_{0 o g} e^{8}$, também são citadas pelos entrevistados em relação aos estudos. Percebemos que auxiliam bastante para organizar conteúdos de sites diversos. Muitos relatam que elas operam como uma porta de entrada para sites a que sequer teriam acesso de outra forma; tanto é que não conseguem recordar a página acessada para obter a informação que necessitam.

É interessante destacarmos que muitos não utilizam a internet. Na verdade, limitam o acesso às mídias sociais pelos smartphones. Dois fatores podem estar associados a essa questão: estar relacionado ao que pesquisadores, como Peruzzo (2005), discorrem a respeito da dificuldade no manuseio da internet por uma parcela da população brasileira, em decorrência da falta de formação ou de recursos financeiros para obter um acesso de boa qualidade; ou estar relacionado à convergência midiática e à construção colaborativa (JENKINS, 2009).

\footnotetext{
${ }^{8}$ www.google.com
} 
Sobre as mídias sociais utilizadas, mais uma vez lideram como preferências dos jovens o WhatsApp, o Facebook e o Instagram, mencionados por quase todos os entrevistados. Nas apropriações e usos, entendemos haver distinção entre os níveis de intimidade: as conversas em grupo e as conversas privadas.

Privado, em grupo, em todo lugar, mas eu gosto mais do privado. Não gosto de tá falando com outras pessoas sem ser próximas... é mais no grupo e no privado com os colegas, marcando os esquemas também assim, né? Mas eu tenho medo de ficar marcando esses encontros pelo WhatsApp. Eu não gosto de mexer muito, mas no Facebook eu também gosto, mas continuo usando para conhecer novas amizades. Depende das amizades também, né? (Entrevistada mulher 7, Nossa Senhora de Lourdes)

Percebemos, assim, finalidades específicas para o uso de canais digitais. O WhatsApp é usado para manter relações já construídas, enquanto o Facebook, para a criar novas amizades. É preciso, contudo, gerenciar suas informações em outros canais, como o Instagram e o Facebook, que para os jovens oferecem mais recursos para expressão das suas subjetividades em comparação ao WhatsApp.

Os grupos nas mídias sociais servem como apoio aos estudos e são mais citados para essa finalidade. O contato com amigos e parentes é também uma questão importante para a criação de grupos, assim como para acompanhar notícias. Por pertencerem a cidades de pequeno porte, as informações locais circulam em grupos de forma mais efetiva em comparação a outros meios.

Por fim, são mencionadas várias finalidades sobre os usos das mídias sociais, como: interações com seus laços fortes, sejam parentes de primeiro grau ou amigos; compartilhamento de fotos ou vídeos, o que vai ao encontro de autores como Bruno (2005), que há muito vem apontando um desejo de querer ver e ser visto que os usuários dessas mídias sociais possuem. Há, assim, alternância na preferência entre postar ou visualizar imagens da sua rede.

Para falar a verdade, eu gosto muito de "curiar" a vida dos outros. Eu gosto muito de curtir os perfis das pessoas. Falo muito com os mais conhecidos (...) Eu costumo compartilhar fotos e vídeos de algum acontecimento... De algum caso sério. (Entrevistada mulher 8, Nossa Senhora de Lourdes)

Muitos mencionam a conversação nas mídias sociais como uma extensão do contato de forma presencial. Há, no entanto, indissociação entre os ambientes digitais e os presenciais. Notamos, assim, o fluxo comunicacional, cujas interações ocorrem de forma mais orgânica, com esses contextos (físico e digital) operando juntos, de forma ininterrupta.

Essas mídias são fortes representações dessas novas interações, pois são dinâmicas e suas transformações refletem as interações entre os indivíduos (RECUERO, 2009). Como resultado da ascensão 


\section{ALCEU}

ISSN: $2175-7402$

da mediação online e das interações presentes nesse meio, temos cada vez mais pessoas utilizando as mídias sociais para se comunicar e até para outras funcionalidades: por exemplo, realizar compras (THOMPSON, 2014). Por outro lado, tivemos jovens da Microrregião que ainda valorizam o consumo no comércio local, especialmente nas feiras comuns em Propriá, caracterizadas como as mais influentes da região, para as quais eles se deslocam de suas cidades. Um padrão de consumo que inclusive se assemelha com outras localidades do interior do país (DA SILVA, 2014).

A extensão no espaço e no tempo também deve ser considerada, pois não é necessário estar online no momento de uma transmissão ao vivo, considerando que o conteúdo pode ficar disponibilizado na rede por tempo indeterminado. O que auxilia os jovens da Microrregião para o consumo de um conteúdo nacional, tendo em vista o relato deles de que não existe uma agenda cultural local que consiga satisfazêlos.

\section{Considerações finais}

A questão da mobilidade se destaca em nossa pesquisa, tendo em vista que, em muitos casos, a preferência pelo acesso a determinado aparelho se deve ao fato de ser utilizado em uma situação de mobilidade, de trânsito. Se, por um lado, a justificativa para isso talvez seja a questão da falta de tempo para se deter a um único aparelho, impedido pela rotina diária de cada um, por outro, podemos inferir que esse aspecto da falta de tempo está associado à "incapacidade" desses jovens em ter atenção voltada a um determinado aparelho. A possibilidade de acessarem aparelhos em situação de mobilidade pode também operar como uma forma de preencher determinado "espaço" da atenção dos jovens, servindo até como um acompanhante em suas rotinas diárias.

Percebemos, de maneira geral, a importância dos dispositivos comunicacionais móveis no consumo de conteúdo dos meios de comunicação de massa, especialmente os smartphones, embora os jovens também mantenham o hábito de acessar aparelhos capazes de prover um único conteúdo (não convergente), ainda que não dediquem uma atenção focada ou única.

Em relação à segunda categoria por nós criada, apontamos de início que é possível ver uma oscilação na preferência dos jovens pela abrangência do conteúdo consumido, ora dando preferência por algo produzido no estado ou em sua Microrregião, ora optando por algo produzido nacional ou 
internacionalmente. Na verdade, o que temos é a linguagem, o tipo de conteúdo e a plataforma de consumo interferindo na preferência dos jovens.

Ao tratarmos da terceira categoria criada para essa pesquisa, pudemos destacar a importância dos dispositivos comunicacionais móveis, em especial os smartphones, no acesso à internet pelos jovens. Nesse aspecto, notamos o uso por meio de redes Wi-Fi ou pacotes de dados móveis, especialmente com duas finalidades: consumo midiático e interlocução com a sua rede social.

$\mathrm{Na}$ quarta categoria, tentamos mapear as relações que os jovens mantêm com grupos sociais, sejam na interação mediada pelas tecnologias digitais, sejam por meio da copresença física. De forma geral, percebemos a importância da mediação dessas tecnologias no contato com seus amigos e colegas do colégio, por meio de mensagens diretas ou grupos do WhatsApp, enquanto ainda se mantém preservada a interação com familiares mais velhos em contextos de copresença física, embora não deixem de manter relações também por meio dos instant messengers.

A última categoria criada em nossa pesquisa refere-se ao uso da internet e das mídias sociais, que mereceu destaque pela centralidade que especialmente as mídias sociais assumem no acesso às TICs pelos jovens. A possibilidade de compartilhar conteúdos do ponto de vista pessoal - viagens, passeios, encontros - com amigos e familiares, dentre outras ações cotidianas, de acessar os perfis e páginas de amigos e celebridades e de manter relações com pessoas geograficamente próximas ou distantes figuraram entre as opções mais apontadas pelos jovens ao fazerem uso dos seus smartphones no acesso à internet.

Couldry e Hepp (2016) já apontavam a centralidade que as mídias sociais assumem nesse contexto contemporâneo, especialmente para as gerações que alcançaram o letramento digital desde a sua formação na infância. Para os autores, trata-se de um movimento da centralidade que os meios de comunicação com contornos massivos tinham em fases anteriores da humanidade para uma relação com as mídias na contemporaneidade em que permitem expressar as subjetividades dos jovens, bem como oferecer uma forma de interlocução ampliada, com múltiplos canais digitais oferecendo serviços de produção e circulação de conteúdo. Algo que pudemos atestar em nossa pesquisa com os jovens dessa região, nos trazendo indícios para compreender como essas mídias promovem um padrão de consumo em escala global. 
ORCID: https://orcid.org/0000-0002-2377-9323 Universidade Federal do Sergipe, Programa de Pós-graduação em Comunicação, São Cristóvão (SE), Brasil. Doutor em Comunicação e Cultura Contemporâneas / UFBA E-mail: vtorbragamg@gmail.com

Matheus P.M. Felizola

ORCID: https://orcid.org/0000-0002-7826-4511 Universidade Federal do Sergipe, Programa de Pós-graduação em Comunicação, São Cristóvão (SE), Brasil. Doutor em Ciências Sociais / UFRN E-mail: contato@matheusfelizola.com

Jane A. Marques

ORCID: https://orcid.org/0000-0003-2382-9041 Universidade de São Paulo, Escola de Artes, Ciências e Humanidades, São Paulo (SP), Brasil. Doutora em Ciências da Comunicação / USP E-mail: janemarq@usp.br

Recebido em: 12 de maio de 2020.

Aprovado em: 30 de julho de 2020.

\section{Referências:}

ANGELUCI, Alan César; GALPERIN, Hernán. O consumo de conteúdo digital em lan houses por adolescentes de classes emergentes no brasil. In: Revista Latinoamericana de Ciencias de la Comunicación, v. 9, n. 17, p. 246-257, 2012.

AQUINO, M. C. Convergência Midiática e Redes Digitais: Modelo de Análise para Pesquisas em Comunicação. Curitiba: Appris, 2017.

BARDIN, L. Análise de conteúdo. São Paulo: Edições 70, 2016.

BATALLA, G. B. México profundo: una civilización negada. 2. ed. Cidade do México: Grijalbo, 1990.

BRUNO, F. Quem está olhando? Variações do público e do privado em weblogs, fotologs e reality shows. Contemporânea: Revista de Comunicação e Cultura, v. 3, n. 2, p. 53-69, 2005. 
CAMARANO, A. A.; ABRAMOVAY, R. Êxodo rural, envelhecimento e masculinização no Brasil: panorama dos últimos 50 anos. Brasília: IPEA, 1999.

CANCLINI, N. G. Culturas Híbridas: Estratégias para Entrar e Sair da Modernidade. São Paulo: Edusp, 2001. . Leitores, espectadores e internutas. São Paulo: Iluminuras, 2008.

2010.

. Consumidores e cidadãos: conflitos multiculturais da globalização. Rio de Janeiro: Editora UFRJ,

CIMADEVILLA, G. !Bienvenidos a la rurbanidad! La Ventana, v. 1, n. 1, 2008.

COULDRY, N.; HEPP, A. The Mediated Construction of Reality. Oxford: Polity Press, 2016.

DA SILVA, Ricardo Duarte. Atravessamento de sentidos e narrativas televisivas no meio rural: interlocuções e valores na dicotomia rural/urbano. In: Anais do III Colóquio Semiótica das Mídias, Japaratinga (AL), v. 1, p. 1-16, 2014.

GEERTZ, C. O saber local: novos ensaios em antropologia interpretativa. Petrópolis: Vozes, 1997.

HUMPHREYS, L. The Qualified Self: Social Media and the Accounting of Everyday Life. Cambridge: MIT Press, 2018.

JACKS, N.; TOALDO, M. Consumo Midiático: uma especificidade do consumo cultural, uma antessala para os estudos de recepção. In: Jovens, Consumo e Convergência Midiática. Curitiba: Editora UFPR, 2017. p. 19-29.

JENKINS, H. Cultura da Convergência. São Paulo: Aleph, 2009.

; GREEN, J.; FORD, S. Cultura da conexão: criando valor e significado por meio da mídia propagável. 1. ed. São Paulo: Aleph, 2014.

LESSARD-HÉRBET, M.; BOUTIN, G.; GOYETTE, G. Investigação Qualitativa: fundamentos e práticas. 5. ed. Lisboa: Instituto Piaget, 1990.

PERUZZO, C. K. Mídia regional e local: aspectos conceituais e tendências. Comunicação \& Sociedade, v. 26, n. 43, p. 67-84, 2005.

RECUERO, R. Redes sociais na internet. Porto Alegre: Sulina, 2009.

SLATER, D. Cultura do consumo \& modernidade. São Paulo: Nobel, 2002.

THOMPSON, J. A Mídia e a Modernidade: uma teoria social da mídia. Petrópolis: Vozes, 2014. 
WEISHEIMER, N. Juventudes rurais: mapa de estudos recentes. Brasília: Ministério do Desenvolvimento Agrário, 2005.

\section{Resumo}

Discutimos o consumo midiático e cultural dos jovens de cidades distantes das regiões metropolitanas, especificamente no Nordeste do Brasil. Compreendemos estar diante de um contexto com particularidades considerando a convergência dos meios e as condições de acesso às TICs. Através de uma pesquisa com inspiração etnográfica, foram aplicadas entrevistas semiestruturadas com jovens de 18 a 24 anos da Microrregião de Propriá (SE), e depois realizada uma análise de conteúdo. Dentre os resultados, pudemos observar um distanciamento gradativo dos jovens da centralidade da mídia de massa, em contraposição a uma aproximação no consumo via dispositivos móveis. O acesso às mídias sociais foi uma variável importante, pois os jovens operam um consumo voltado à interação com suas redes; se representam em um contexto de grande exposição de si mesmo; e não se distanciam dos referenciais da cultura regional que vivenciam.

Palavras-chave: Consumo midiático. Mídias sociais. Jovens. Nordeste brasileiro. Sergipe.

\section{Abstract}

We discuss the media and cultural consumption of young people from cities far from metropolitan regions, specifically in the Northeast of Brazil. We understand that we are facing a context with particularities considering the convergence of the means and the conditions of access to ICTs. Through an ethnographic research, semi-structured interviews were conducted with young people from 18 to 24 years old from the Microregion of Propriá (SE), and then a content analysis was performed. Among the results, we could observe a gradual distancing of young people from the centrality of mass media, as opposed to an approximation of consumption via mobile devices. Access to social media was an important variable because young people operate a consumption focused on interaction with their networks; represent themselves in a context of great selfexposure; and do not deviate from the references of the regional culture they experience.

Keywords: Media consumption. Social media. Youth. Brazilian Northeast. Sergipe. 


\section{Resumen}

Discutimos el consumo de medios y cultura de los jóvenes de ciudades lejanas de las regiones metropolitanas, específicamente en el noreste de Brasil. Comprendemos que nos enfrentamos a un contexto com particularidades teniendo en cuenta la convergencia de los medios y las condiciones de acceso a las TIC. A través de una encuesta de inspiración etnográfica, se aplicaron entrevistas semiestructuradas a jóvenes de 18 a 24 años de la Microrregión de Propriá (SE), y luego se realizó un análisis de contenido. Entre los resultados, pudimos observar un distanciamiento gradual de los jóvenes de la centralidad de los medios de comunicación, en oposición a un enfoque de consumo a través de dispositivos móviles. El acceso a las redes sociales era una variable importante, ya que los jóvenes manejan el consumo destinado a interactuar con sus redes; representarse a sí mismos en un contexto de gran exposición de sí mismos; y no están lejos de las referencias de la cultura regional que experimentan.

Palavras clave: Consumo de médios. Redes sociales. Jovenes. Nordeste brasileño. Sergipe.

Este artigo é publicado em acesso aberto (Open Access) sob a licença Creative Commons Attribution Non-Commercial (CC-BY-NC 4.0), que permite que outros remixem, adaptem e criem a partir do seu trabalho para fins não comerciais, e embora os novos trabalhos tenham de lhe atribuir o devido crédito e não possam ser usados para fins comerciais, os usuários não têm de licenciar esses trabalhos derivados sob os mesmos termos. 